\title{
Is There a Difference in Revision Risk Between Metal and Ceramic Heads on Highly Crosslinked Polyethylene Liners?
}

\author{
Guy Cafri PhD, MStat, Elizabeth W. Paxton MA, Rebecca Love MPH, RN, \\ Stefano A. Bini MD, Steven M. Kurtz PhD
}

Published online: 6 July 2016

(C) The Association of Bone and Joint Surgeons ( 2016

\begin{abstract}
Background The most common bearing surface used among primary THAs worldwide is a metal or ceramic femoral head that articulates against a highly crosslinked ultrahigh-molecular-weight polyethylene (HXLPE) acetabular liner. Despite their widespread use, relatively little is known about the comparative effectiveness of ceramic versus metal femoral heads with respect to risk of revision and dislocation as well as the role of head size in this relationship. Questions/purposes The purpose of this study was to evaluate the risk of (1) all-cause revision in metal versus ceramic femoral heads when used with an HXLPE liner, including an evaluation of the effect of head size; and (2) dislocation in metal versus ceramic femoral heads when
\end{abstract}

One of the authors (SMK) is an employee and shareholder of Exponent, Inc (Menlo Park, CA, USA) and received institutional support from Smith \& Nephew (Memphis, TN, USA), Stryker (Mahwah, NJ, USA), Zimmer Biomet (Warsaw, IN, USA), DePuy Synthes (Warsaw, IN, USA), Medtronic (Memphis, TN, USA), Invibio (Thornton Cleveleys, UK), Stelkast (McMurray, PA, USA), Formae (Paoli, PA, USA), Kyocera Medical (Kyoto, Japan), Wright Medical Technology (Memphis, TN, USA), Ceramtec (Plochingen, Germany), DJO (Vista, CA, USA), Celanese

(Florence, KY, USA), Aesculap (Tuttlingen, Germany), Spinal

Motion (Mountain View, CA, USA), Active Implants (Memphis, TN, USA), and Ferring Pharmaceuticals (Parsippany, NJ, USA) outside the submitted work.

All ICMJE Conflict of Interest Forms for authors and Clinical Orthopaedics and Related Research $\mathbb{\AA}$ editors and board members are on file with the publication and can be viewed on request. Clinical Orthopaedics and Related Research $\mathbb{R}$ neither advocates nor endorses the use of any treatment, drug, or device. Readers are encouraged to always seek additional information, including FDAapproval status, of any drug or device prior to clinical use.

Each author certifies that his or her institution approved or waived approval for the human protocol for this investigation and that all investigations were conducted in conformity with ethical principles of research. used with an HXLPE liner as well as an assessment of the effect of head size.

Methods Data were collected as part of the Kaiser Permanente Total Joint Replacement Registry between 2001 and 2013. Patients in this study were on average overweight (body mass index $=29 \mathrm{~kg} / \mathrm{m}^{2}$ ), 67 years old, mostly female (57\%), and had osteoarthritis $(93 \%)$ as the primary indication for surgery. The material of the femoral head (metal, ceramic) was crossed with head size $(<32,32,36$, $>36 \mathrm{~mm}$ ), yielding eight device groupings. Only uncemented devices were evaluated. The primary outcome was all-cause revision $(\mathrm{n}=28,772)$ and the secondary outcome was dislocation within 1 year $(\mathrm{n}=19,623)$. Propensity

This work was performed at Surgical Outcomes \& Analysis, Kaiser Permanente, San Diego, CA, USA.

Electronic supplementary material The online version of this article (doi:10.1007/s11999-016-4966-1) contains supplementary material, which is available to authorized users.

G. Cafri ( $\square$ ), E. W. Paxton, R. Love

Surgical Outcomes \& Analysis, Kaiser Permanente, 8954 Rio

San Diego Drive, San Diego, CA 92018, USA

e-mail: Guy.X.Cafri@kp.org

S. A. Bini

University of California at San Francisco, San Francisco, CA, USA

S. M. Kurtz

Drexel University, Philadelphia, PA, USA

S. M. Kurtz

Exponent, Inc, Philadelphia, PA, USA 
scores were used to adjust for potential confounding at the implant/patient level using between-within semiparametric survival models that control for surgeon and hospital confounding and adjust estimates for the within-cluster correlation among observations on the response.

Results For all-cause revision, there was no difference between ceramic versus metal (reference) heads in combination with an HXLPE liner (hazard ratio [HR] $=0.82[0.65-$ 1.04], $\mathrm{p}=0.099$ ). Smaller metal head sizes of $<32 \mathrm{~mm}$ were associated with increased risk of revision relative to $36 \mathrm{~mm}$ $(\mathrm{HR}=1.66[1.20-2.31], \mathrm{p}=0.002$, adjusted $\mathrm{p}=0.025)$. For dislocation, ceramic heads increased risk relative to metal at $<$ $32 \mathrm{~mm}$ only (HR $=4.39$ [1.72-11.19], $\mathrm{p}=0.002$, adjusted $\mathrm{p}=$ $0.020)$. Head sizes $<32 \mathrm{~mm}$ were associated with increased risk of dislocation relative to $36 \mathrm{~mm}$ for metal $(\mathrm{HR}=2.99$ [1.40-6.39], $\mathrm{p}=0.005$, adjusted $\mathrm{p}=0.047$ ) and ceramic heads (HR $=15.69$ [6.07-40.55], $\mathrm{p}<0.001$, adjusted $\mathrm{p}<0.001)$.

Conclusions The results did not provide evidence for use of one femoral head material over another when used with HXLPE liners for the outcome of revision, but for dislocation, metal performed better than ceramic with $<32-\mathrm{mm}$ heads. Overall, the findings suggest increased risk of revision/dislocation with head sizes $<32 \mathrm{~mm}$.

Level of Evidence Level III, therapeutic study.

\section{Introduction}

The most common bearing surface used among primary THAs worldwide is a metal or ceramic femoral head that articulates against a highly crosslinked ultrahigh-molecular-weight polyethylene (HXLPE) acetabular liner $[2,3,27,28]$. When used in a THA articulation against HXLPE, metal heads typically include an alloy of cobalt, chromium, and molybdenum, whereas ceramic heads may be alumina, zirconia, zirconia-toughened alumina matrix composite, or oxidized zirconium [15]. In the United States and several other countries around the world, the most popular liner is HXLPE (irradiated dose of $>40 \mathrm{kGy}$ ) $[15,27,28]$. HXLPE liners typically are used with either a metal-alloy femoral head and less frequently with a ceramic head [15]. The use of HXLPE rather than conventional UHMWPE is supported by simulator studies reporting decreased femoral penetration and wear in HXLPE $[9,22,24,25]$, radiologic evaluations of in vivo liner wear in randomized controlled trials indicating lower wear in HXLPE [6-8, 10, 20, 21, 26, 35], meta-analyses and systematic reviews suggesting that HXLPE has lower femoral penetration and wear [16, 17, 23], and registry-based studies showing a decreased risk of revision in HXLPE $[28,32]$.

There has been limited research related to the comparative safety/effectiveness of metal versus ceramic heads in combination with HXLPE liners. Theoretical advantages of ceramic compared with metal heads are that the smooth finish, hardness, and wettability lead to less friction, more lubrication, and less scratching between the bearing surfaces and thus lower rates of liner wear and osteolysis [37], although this is based on use of historical UHMWPE (gamma air-sterilized polyethylene) and older manufacturing processes of femoral heads that may not generalize to contemporary implants. One of the major concerns about ceramic heads, especially in ceramic-on-ceramic articulation, is the risk of component fracture; however, this has shown to be decreased in ceramic-on-polyethylene bearing surfaces $[1,39]$. Results from the Australian registry suggest that ceramic heads have a slightly higher revision risk among patients with osteoarthritis over a 10-year period when used with HXLPE (gender/age-adjusted hazard ratio [HR], 1.03; 95\% confidence interval, 0.94-1.13) [28]. Although informative, these results only adjust for age and gender, not considering the possible differential or confounding effects of head size or other factors on revision risk. Femoral head size is particularly relevant to the extent that larger heads have been shown to improve stability and thereby reduce risk of dislocation and revision $[4,5,14,27]$. Collectively, there is relatively little research that can inform clinical practice about the most safe/effective femoral component types in the most common practice settings.

The current study evaluates risk of all-cause revision (primary endpoint) as well as dislocation (secondary endpoint) comparing metal and ceramic heads when used with HXLPE liners. To the extent that size is an attribute of a femoral head, any bearing effect could depend on size, but even in the absence of such interactive effects, it would be important to adjust for possible confounding head size effects (as well as confounding effects of other variables). Separately from any effect of the bearing, it is also of interest to determine to what extent changes in head size lead to improved implant performance. Specifically, we evaluated the risk of (1) all-cause revision in metal versus ceramic femoral heads when used with an HXLPE liner, including an evaluation of the effect of head size; and (2) dislocation in metal versus ceramic femoral heads when used with an HXLPE liner as well as an assessment of the effect of head size.

\section{Materials and Methods}

An integrated healthcare system total joint replacement registry (Kaiser Permanente Total Joint Registry) was used to identify a cohort of patients with primary elective unilateral THAs from April 1, 2001, to December 31, 2013, who were followed longitudinally. The study sample included arthroplasties from 358 surgeons at 50 medical 
centers in seven US geographic regions (southern and northern California, Colorado, Georgia, Hawaii, Northwest, mid-Atlantic). During the study period, the membership population in these regions was between 8.3 and over 9 million. A subsample consisting of operative dates from January 1, 2007, to December 31, 2013, for southern California, northern California, and Hawaii was used to evaluate dislocations because information on this outcome in the healthcare system only became available at this later time. The Registry consists of standardized operative data collected from the surgeon by paper or electronically at the time of surgery [30, 31, 33, 34]. The participation of surgeons is voluntary and was $95 \%$ for the THAs. The registry is able to follow $91 \%$ of primary elective unilateral THAs with the remainder lost to followup as a result of membership termination. The forms capture information on patient demographics, surgical technique, implant characteristics, and patient outcome. Registry data are validated using the hospital utilization database and independent chart review.

Included in the sample were only individuals with uncemented fixation (and HXLPE liners), because cement fixation on either the cup or stem was rarely used in combination with ceramic heads in the registry. We also only included patients with a diagnosis of osteoarthritis, avascular necrosis, rheumatoid arthritis, inflammatory arthritis, and posttraumatic arthritis.

The exposure of interest was based on crossing femoral material (ceramic versus metal) and head size $(<32 \mathrm{~mm}$, $32 \mathrm{~mm}, 36 \mathrm{~mm},>36 \mathrm{~mm}$ ), yielding a total of eight groups.
Ceramic heads were either alumina $(\mathrm{N}=222)$ or zirconiatoughened alumina matrix composite $(\mathrm{N}=5875)$. Ceramic and metal heads were predominantly from the following manufacturers: Zimmer/Biomet (Warsaw, IN, USA), Smith \& Nephew (Memphis, TN, USA), DePuy (Warsaw, IN, USA), and Stryker/Howmedica (Kalamazoo, MI, USA) with three or fewer implants from each of the following: Wright Medical (Memphis, TN, USA), OMNIlife science (East Taunton, MA, USA), and Link (Hamburg, Germany). Similar to reports from another registry [28], oxidized zirconium was not included in the ceramic head group for several reasons: the material is proprietary to a single company, the volume of use in the registry is too low to form its own set of groups, and the effectiveness of the material may be substantially better than other ceramics, which would introduce treatment heterogeneity if pooled with other ceramic materials [28]. Zirconia was not included because it is no longer being used, corresponding to a recall in 2001 resulting from increasing component fractures attributable to a change in the manufacturing process from the largest supplier [15].

Variables regarded as potential confounders of the relationship between the treatment and the outcomes of interest included: age, sex, race (white versus other), diagnosis (osteoarthritis versus other), body mass index, height, American Society of Anesthesiologists score $(<3$ versus $\geq 3$ ), diabetes (yes versus no), operative time, and surgical approach (posterior versus any other approach) (Table 1). The outcome of primary interest was time to first revision, defined as replacement of any component for any

Table 1. Descriptive characteristics of the sample (listwise deleted data)

\begin{tabular}{|c|c|c|c|c|}
\hline Characteristic & \multicolumn{2}{|c|}{ Revision sample, number (\%) } & \multicolumn{2}{|c|}{ Dislocation sample, number $(\%)$} \\
\hline Total & $28,772(100.0)$ & & $19,623(100)$ & \\
\hline Diabetes & $5324(19)$ & & $3607(18)$ & \\
\hline ASA score $\geq 3$ & $10,637(38)$ & & $7378(38)$ & \\
\hline Male & $12,260(43)$ & & $8280(42)$ & \\
\hline White & $22,960(80)$ & & $15,255(78)$ & \\
\hline Osteoarthritis & $26,770(93)$ & & $18,359(94)$ & \\
\hline Posterior approach & $21,124(77)$ & & $15,311(81)$ & \\
\hline Characteristic & & Mean (SD) & & Mean (SD) \\
\hline Height (inches) & & $67(4)$ & & $67(4)$ \\
\hline Age (years) & & $67(11)$ & & $67(11)$ \\
\hline BMI $\left(\mathrm{kg} / \mathrm{m}^{2}\right)$ & & $29(6)$ & & $29(6)$ \\
\hline Operative time (minutes) & & $90(33)$ & & $88(32)$ \\
\hline $\begin{array}{l}\text { Surgeries performed by surgeon at } \\
\text { the time of surgery }\end{array}$ & & $191(179)$ & & $201(187)$ \\
\hline
\end{tabular}

Revision sample, number, missing: 771 ASA, 84 race, 1326 approach, 514 height, 2989 operative time, 517 BMI; dislocation sample, number, missing: 410 ASA, 3 race, 768 approach, 16 height, 976 operative time, 15 BMI; ASA = American Society of Anesthesiologists; BMI = body mass index. 
reason, which was confirmed by chart review. The secondary outcome of interest was dislocation within 1 year of implantation (Table 2). Dislocations were identified based on International Classifications of Disease, $9^{\text {th }}$ Revision, Clinical Modification codes $718.35,835^{*}$, or 996.42 .

\section{Statistical Analysis}

Survival analysis was performed with a semiparametric between-within model [38]. The model included an unspecified baseline hazard, fixed effects corresponding to patient treatment group (seven coefficients corresponding to the eight treatment groups), surgeon and hospital means that reflect the proportion of patients receiving treatment in each cluster, propensity score weights, and normal crossclassified random effects for surgeon and hospital. This between-within model allows interpretation of patient treatment effects as within-patient effects that cannot be confounded by fixed surgeon and hospital characteristics. Loss to followup (either date of membership termination or death) was treated as censored cases with survival time based on the time those cases exited the study sample. For member terminations, this approach assumes that those who terminate membership have a survival prospect similar to those experiencing events. In contrast, death represents a competing event, suggesting a competing risk model would be more appropriate. A competing risk model, however, would conflate the treatment effect with the probability of experiencing the competing event; therefore, the approach taken in this study was a more direct estimate of treatment effectiveness [18]. To account for missing values of some variables, multiple imputations
(20 imputations, 10 iterations) were performed using chained equations [40]. Imputations were undertaken separately for each of the two outcomes. Generally, the imputation model for each outcome included patient treatment assignment and covariates, surgeon and facility means corresponding to these variables as well as the event indicator, and the Nelson-Aalen estimator of the cumulative baseline hazard at the time of the event being modeled or censoring for each case [41]. Average treatment effect propensity score weights $[12,13]$ were calculated separately for each imputed data set using a multinomial logistic regression model that included all covariates as predictors of treatment assignment. This approach to calculating propensity score weights ensures each group has comparators in each of the other treatment groups (ie, within 0.20 SDs of the logit propensity score), which reduces bias, and calculating weights through stratification (six strata) has the advantage of being less sensitive to misspecification of the propensity score model $[12,13]$. There was notable improvement in balance after applying the propensity score weights. For example in the revision sample for 10 bearing/head size comparisons on each of the 10 covariates, before applying weights, the mean standardized difference was $0.20(\mathrm{SD}=0.21)$, but after applying weights, the mean standardized difference was $0.04(\mathrm{SD}=0.04)$.

To limit Type I errors, global tests were used with followup pairwise comparisons conducted conditional on a statistically significant global test. Probabilities from these pairwise comparisons were adjusted using Holm's sequential Bonferroni procedure [11] based on the total number of pairwise comparisons conducted. Global tests and pairwise comparisons were based on results aggregated

Table 2. Analytical sample sizes and cases revised by femoral head material and head size

\begin{tabular}{lll}
\hline Head size & Femoral head material & Metal \\
\cline { 2 - 3 } & Ceramic & $\mathrm{N}=22,675$, revised $=515(2.3 \%)$ \\
\hline Revision & $\mathrm{N}=6097$, revised $=128(2.1 \%)$ & $\mathrm{N}=2880$, revised $=101(3.5 \%)$ \\
$<32 \mathrm{~mm}$ & $\mathrm{~N}=468$, revised $=9(1.9 \%)$ & $\mathrm{N}=8476$, revised $=193(2.3 \%)$ \\
$32 \mathrm{~mm}$ & $\mathrm{~N}=2072$, revised $=61(2.9 \%)$ & $\mathrm{N}=10,242$, revised $=194(1.9 \%)$ \\
$36 \mathrm{~mm}$ & $\mathrm{~N}=3239$, revised $=49(1.5 \%)$ & $\mathrm{N}=1077$, revised $=27(2.5 \%)$ \\
$>36 \mathrm{~mm}$ & $\mathrm{~N}=318$, revised $=9(2.8 \%)$ & $\mathrm{N}=15,292$, dislocation $=196(1.3 \%)$ \\
Dislocation & $\mathrm{N}=4331$, dislocation $=42(1.0 \%)$ & $\mathrm{N}=1215$, dislocation $=16(1.3 \%)$ \\
$<32 \mathrm{~mm}$ & $\mathrm{~N}=249$, dislocation $=7(2.8 \%)$ & $\mathrm{N}=5633$, dislocation $=80(1.5 \%)$ \\
$32 \mathrm{~mm}$ & $\mathrm{~N}=1507$, dislocation $=17(1.1 \%)$ & $\mathrm{N}=7620$, dislocation $=85(1.2 \%)$ \\
$36 \mathrm{~mm}$ & $\mathrm{~N}=2363$, dislocation $=17(0.7 \%)$ & $\mathrm{N}=824$, dislocation $=15(2.1 \%)$ \\
\hline $36 \mathrm{~mm}$ & $\mathrm{~N}=212$, dislocation $=1(0.5 \%)$ & \\
\hline
\end{tabular}

Followup time for implants as it pertains to revision (in years): median $=4.6, \mathrm{SD}=3.4$, maximum $=11.6($ ceramic $<32)$; median $=3.2, \mathrm{SD}=2.8$, maximum $=11.2($ ceramic $=32) ;$ median $=2.05, \mathrm{SD}=1.8$, maximum $=9.9($ ceramic $=36)$; median $=1.9, \mathrm{SD}=1.2$, maximum $=5.5($ ceramic $>$ $36)$; median $=5.9, \mathrm{SD}=3.5$, maximum $=12.7($ metal $<32)$; median $=3.8, \mathrm{SD}=2.9$, maximum $=12.6($ metal $=32) ;$ median $=2.8, \mathrm{SD}=2.2$, maximum $=11.5($ metal $=36) ;$ and median $=2.8, \mathrm{SD}=1.7$, maximum $=9.9($ metal $>36)$. 
over imputed data sets [36]. When reporting the bearing effect averaged over head size, the effect of the bearing was first estimated within each head size stratum and then averaged over strata using inverse variance weights. Data were analyzed using the mice, miceadds, and coxme packages of R (R Version 3.1.2; R Foundation for Statistical Computing) with $\alpha=0.05$ (two-tailed).

\section{Results}

\section{All-cause Revision}

The first research question pertains to whether there is a difference between metal and ceramic heads with respect to risk to all-cause revision. Generally, there was insufficient evidence of a difference in revision risk between metal and ceramic heads in the statistical model that adjusted for potential confounding variables. The ceramic versus metal (reference) effect averaged over head size groups was not significant (HR $=0.82$ [0.65-1.04]; $\mathrm{p}=0.099)$ (reasons for revision are in Table 3).

With regard to whether increasing head size reduces risk of revision, after adjusting for potential confounders, there was evidence that among metal heads, going from $36 \mathrm{~mm}$ to $<32 \mathrm{~mm}$ was harmful ( $\mathrm{HR}=1.66[1.20-2.31]$, $\mathrm{p}=$ 0.002 , adjusted $p=0.025$ ). See Appendix 1 for further details regarding the analysis (Supplemental materials are available with the online version of $C O R R^{\circledR}$.).

Dislocation

There was evidence of a difference between metal and ceramic heads with respect to risk of dislocation, but the effect was not the same across the head size groups. It was found that ceramic heads performed notably worse than metal at $<32 \mathrm{~mm}$ only $(\mathrm{HR}=4.39$ [1.72-11.19], $\mathrm{p}=0.002$, adjusted $\mathrm{p}=0.020$ ). Generally, there was evidence that $<$ $32 \mathrm{~mm}$ relative to $36 \mathrm{~mm}$ increased risk of dislocation for both metal (HR = 2.99 [1.40-6.39], $\mathrm{p}=0.005$, adjusted $\mathrm{p}=$ 0.047) and ceramic heads $(\mathrm{HR}=15.69$ [6.07-40.55], $\mathrm{p}<$ 0.001 , adjusted $\mathrm{p}<0.001$ ). See Appendix 1 for further details regarding the analysis.

\section{Discussion}

A study such as this one is important in the postmarket surveillance of orthopaedic devices because the femoral head of a THA is an important determinant of device survival. Relatively little is known about the comparative effectiveness of ceramic versus metal femoral heads when used with HXLPE liners with only one registry report

Table 3. Reasons for revision

\begin{tabular}{|c|c|c|c|}
\hline & Overall & Metal & Ceramic \\
\hline Number & 28,772 & 22,675 & 6097 \\
\hline Revision & $643(2.2)$ & $515(2.3)$ & $128(2.1)$ \\
\hline Reason & Number $(\%)$ & Number $(\%)$ & Number $(\%)$ \\
\hline Leg length inequality & $8(1.2)$ & $8(1.6)$ & $0(0.0)$ \\
\hline Acetabular fracture & $2(0.3)$ & $2(0.4)$ & $0(0.0)$ \\
\hline Aseptic loosening & $71(11)$ & $61(12)$ & $10(8)$ \\
\hline Component fracture & $10(1.6)$ & $6(1.2)$ & $4(3)$ \\
\hline Femoral fracture & $25(4)$ & $20(4)$ & $5(4)$ \\
\hline Infection & $155(24)$ & $126(25)$ & $29(23)$ \\
\hline Instability & $236(37)$ & $198(38)$ & $38(30)$ \\
\hline Polyethylene insert wear & $26(4)$ & $16(3)$ & $10(8)$ \\
\hline Osteolysis & $5(0.8)$ & $2(0.4)$ & $3(2)$ \\
\hline Other & $32(5)$ & $29(6)$ & $3(2)$ \\
\hline Periprosthetic fracture & $83(13)$ & $68(13)$ & $15(12)$ \\
\hline Wound dehiscence & $2(0.3)$ & $2(0.4)$ & $0(0.0)$ \\
\hline Wound drainage & $22(3)$ & $18(4)$ & $4(3)$ \\
\hline Hematoma/seroma & $37(6)$ & $29(6)$ & $8(6)$ \\
\hline Cup malposition & $3(0.5)$ & $3(0.6)$ & $0(0.0)$ \\
\hline Metallosis & $2(0.3)$ & $1(0.2)$ & $1(0.8)$ \\
\hline
\end{tabular}

There may be multiple reasons for revision. 
providing evidence [28] but with limited adjustment of potential confounders. Similar gaps in the literature can be found as they relate to the effect of femoral head size and the outcome of dislocation. Collectively, increased research into the most effective hip components should lead to the reduction of adverse events experienced by patients. The results suggest no difference between metal and ceramic heads with respect to all-cause revision, but increased risk of dislocation in $<32-\mathrm{mm}$ heads for ceramic relative to metal heads. Furthermore, use of head sizes $<32$ $\mathrm{mm}$ (relative to $36 \mathrm{~mm}$ ) led to increased risk of all-cause revision for metal and increased risk of dislocation for both metal and ceramic heads.

Our study has several limitations. First, in this study, dislocations were limited to within 1 year of the index procedure, which may miss later occurring instances of these adverse events $[19,20,29,30]$. Therefore, any conclusions should be restricted to early dislocations. Furthermore, our study included only uncemented implants. Although this limits generalizability of the results, uncemented implants are most commonly used. Another limitation is the possibility of residual confounding resulting from unmeasured confounders. One such potential confounder is physical activity. For instance, the use of ceramic heads may be used preferentially with more physically active individuals because of the presumed benefit of reduced liner wear. Although physical activity may be difficult to quantify, it would be an interesting factor to pursue in future studies.

For the primary endpoint of all-cause revision, there was a lack of evidence for a difference between ceramic and metal (reference) heads ( $\mathrm{HR}=0.82[0.65-1.04]$ ), which is similar to findings from the Australian registry $(\mathrm{HR}=1.03$ [0.94-1.13]) [28]. It should be noted, however, that there are differences among these two studies, including differences in patient/surgeon/hospital populations, distribution of ceramic types (Australia's ceramic group includes zirconia [28]), length of followup, and different statistical models. With respect to modeling, we believe our approach was somewhat more rigorous in addressing confounding given the adjustment to a greater number of measured variables and a modeling approach that controls for clusterlevel confounders. For the secondary endpoint of dislocation, the results also indicate increased risk with $<32-\mathrm{mm}$ heads relative to $36 \mathrm{~mm}$. Generally, reduction of revision risk and dislocation with a larger head size is consistent with results reported elsewhere [4, 14], but again we believe our approach to handling confounding was more rigorous in the current study, suggesting greater accuracy in the reported results. Although we observed improved performance with respect to dislocation with $36-\mathrm{mm}$ heads relative to $<32 \mathrm{~mm}$, it should be noted that longer term followup may suggest a different result. Notably, the more intermediate head size of $32 \mathrm{~mm}$ was found most effective with respect to reducing risk of revision among metal and ceramic heads used with polyethylene liners with up to 11 years followup [27], but without any adjustment for potential confounders.

Based on our findings, several recommendations can be made for clinical practice and research. Generally, our findings suggest cautious use of head sizes $<32 \mathrm{~mm}$. Furthermore, we cannot recommend one femoral head material over another (ceramic, metal) when used with HXLPE liners in head sizes $\geq 32 \mathrm{~mm}$, but this topic should be investigated further in future studies. Future studies could also examine the effectiveness of femoral head material under more diverse practice settings, for example when used with different bone fixation methods and in older patient populations.

Acknowledgments Special thanks to the staff in the surgical outcomes and analysis department.

\section{References}

1. Amanatullah DF, Landa J, Strauss EJ, Garino JP, Kim SH, Di Cesare PE. Comparison of surgical outcomes and implant wear between ceramic-ceramic and ceramic-polyethylene articulations in total hip arthroplasty. $J$ Arthroplasty. 2011;26:72-77.

2. Bozic KJ, Kurtz S, Lau E, Ong K, Chiu V, Vail TP, Rubash HE, Berry DJ. The epidemiology of bearing surface usage in total hip arthroplasty in the United States. J Bone Joint Surg Am. 2009;91:1614-1620.

3. Bozic KJ, Ong K, Lau E, Kurtz SM, Vail TP, Rubash HE, Berry DJ. Risk of complication and revision total hip arthroplasty among Medicare patients with different bearing surfaces. Clin Orthop Relat Res. 2010;468:2357-2362.

4. Conroy JL, Whitehouse SL, Graves SE, Pratt NL, Ryan P, Crawford RW. Risk factors for revision for early dislocation in total hip arthroplasty. J Arthroplasty. 2008;23:867-872.

5. Crowninshield RD, Maloney WJ, Wentz DH, Humphrey SM, Blanchard CR. Biomechanics of large femoral heads: what they do and don't do. Clin Orthop Relat Res. 2004;429:102-107.

6. Digas G, Kärrholm J, Thanner J, Herberts P. 5-year experience of highly cross-linked polyethylene in cemented and uncemented sockets: two randomized studies using radiostereometric analysis. Acta Orthop. 2007;78:746-754.

7. Digas G, Karrholm J, Thanner J, Malchau H, Herberts P. Highly cross-linked polyethylene in cemented THA: randomized study of 61 hips. Clin Orthop Relat Res. 2003;417:126-138.

8. Digas G, Karrholm J, Thanner J, Malchau H, Herberts P. The Otto Aufranc Award. Highly cross-linked polyethylene in total hip arthroplasty: randomized evaluation of penetration rate in cemented and uncemented sockets using radiostereometric analysis. Clin Orthop Relat Res. 2004;429:6-16.

9. Geerdink CH, Grimm B, Ramakrishnan R, Rondhuis J, Verburg AJ, Tonino AJ. Crosslinked polyethylene compared to conventional polyethylene in total hip replacement: pre-clinical evaluation, in-vitro testing and prospective clinical follow-up study. Acta Orthop. 2006;77:719-725.

10. Heisel C, Silva M, dela Rosa MA, Schmalzried TP. Short-term in vivo wear of cross-linked polyethylene. J Bone Joint Surg Am. 2004;86:748-751. 
11. Holm S. A simple sequentially rejective multiple test procedure. Scand. J. Stat. 1979:65-70.

12. Hong G. Marginal mean weighting through stratification: adjustment for selection bias in multilevel data. J. Educ. Behav. Stat. 2010:499-531.

13. Hong G. Marginal mean weighting through stratification: a generalized method for evaluating multivalued and multiple treatments with nonexperimental data. Psychol Methods. 2012;17:44-60.

14. Kostensalo I, Junnila M, Virolainen P, Remes V, Matilainen M, Vahlberg T, Pulkkinen P, Eskelinen A, Mäkelä KT. Effect of femoral head size on risk of revision for dislocation after total hip arthroplasty: a population-based analysis of 42,379 primary procedures from the Finnish Arthroplasty Register. Acta Orthop. 2013;84:342-347.

15. Kurtz S. The UHMWPE Biomaterials Handbook: Ultra-high Molecular Weight Polyethylene in Total Joint Replacement and Medical Devices. Burlington, MA, USA: Academic Press; 2009.

16. Kurtz SM, Gawel HA, Patel JD. History and systematic review of wear and osteolysis outcomes for first-generation highly crosslinked polyethylene. Clin Orthop Relat Res. 2011;469:22622277.

17. Kuzyk PR, Saccone M, Sprague S, Simunovic N, Bhandari M, Schemitsch EH. Cross-linked versus conventional polyethylene for total hip replacement: a meta-analysis of randomised controlled trials. J Bone Joint Surg Br. 2011;93:593-600.

18. Latouche A, Boisson V, Chevret S, Porcher R. Misspecified regression model for the subdistribution hazard of a competing risk. Stat Med. 2007:965-974.

19. Malkani AL, Ong KL, Lau E, Kurtz SM, Justice BJ, Manley MT. Early- and late-term dislocation risk after primary hip arthroplasty in the Medicare population. $J$ Arthroplasty. 2010;25:21-25.

20. Manning DW, Chiang PP, Martell JM, Galante JO, Harris WH. In vivo comparative wear study of traditional and highly crosslinked polyethylene in total hip arthroplasty. J Arthroplasty. 2005;20:880-886.

21. McCalden RW, MacDonald SJ, Rorabeck CH, Bourne RB, Chess DG, Charron KD. Wear rate of highly cross-linked polyethylene in total hip arthroplasty. A randomized controlled trial. $J$ Bone Joint Surg Am. 2009;91:773-782.

22. McKellop H, Shen F-W, Lu B, Campbell P, Salovey R. Development of an extremely wear-resistant ultra high molecular weight polyethylene for total hip replacements. J Orthop Res. 1999;17:157-167.

23. Mu Z, Tian J, Wu T, Yang J, Pei F. A systematic review of radiological outcomes of highly cross-linked polyethylene versus conventional polyethylene in total hip arthroplasty. Int Orthop. 2009;33:599-604.

24. Muratoglu OK, Bragdon CR, O'Connor DO, Jasty M, Harris WH. A novel method of cross-linking ultra-high-molecular-weight polyethylene to improve wear, reduce oxidation, and retain mechanical properties: recipient of the 1999 HAP Paul Award. $J$ Arthroplasty. 2001;16:149-160.

25. Muratoglu OK, O'Connor DO, Bragdon CR, Delaney J, Jasty M, Harris WH, Merrill E, Venugopalan P. Gradient crosslinking of UHMWPE using irradiation in molten state for total joint arthroplasty. Biomaterials. 2002;23:717-724.
26. Mutimer J, Devane PA, Adams K, Horne JG. Highly crosslinked polyethylene reduces wear in total hip arthroplasty at 5 years. Clin Orthop Relat Res. 2010;468:3228-3233.

27. National Joint Registry for England Wales and Northern Ireland. 12th Annual Report. Herfordshire, UK; 2015. Available at: Available at: http://www.njrcentre.org.uk/njrcentre/Portals/0/Do cuments/England/Reports/12th\%20annual\%20report/NJR\%20O nline\%20Annual\%20Report\%202015.pdf. Accessed May 12, 2016.

28. National Joint Replacement Registry. 2014 Annual Report. Adelaide, Australia; 2014. Available at: https://aoanjrr.dmac. adelaide.edu.au/en/annual-reports-2014. Accessed November 2015.

29. Ong KL, Kurtz SM, Lau E, Bozic KJ, Berry DJ, Parvizi J. Prosthetic joint infection risk after total hip arthroplasty in the Medicare population. J Arthroplasty. 2009;24:105-109.

30. Paxton EW, Inacio MC, Khatod M, Yue EJ, Namba RS. Kaiser Permanente National Total Joint Replacement Registry: aligning operations with information technology. Clin Orthop Relat Res. 2010;468:2646-2663.

31. Paxton EW, Inacio MC, Kiley ML. The Kaiser Permanente Implant Registries: effect on patient safety, quality improvement, cost effectiveness, and research opportunities. Perm J. 2012;16:36-44.

32. Paxton EW, Inacio MC, Namba RS, Love R, Kurtz SM. Metalon-conventional polyethylene total hip arthroplasty bearing surfaces have a higher risk of revision than metal-on-highly crosslinked polyethylene: results from a US registry. Clin Orthop Relat Res. 2015;473:1011-1021.

33. Paxton EW, Inacio MC, Slipchenko T, Fithian DC. The Kaiser Permanente National Total Joint Replacement Registry. Perm J. 2008;12:12-16.

34. Paxton EW, Namba RS, Maletis GB, Khatod M, Yue EJ, Davies M, Low RB Jr, Wyatt RW, Inacio MC, Funahashi TT. A prospective study of 80,000 total joint and 5000 anterior cruciate ligament reconstruction procedures in a community-based registry in the United States. J Bone Joint Surg Am. 2010;92(Suppl 2):117-132.

35. Röhrl S, Nivbrant B, Mingguo L, Hewitt B. In vivo wear and migration of highly cross-linked polyethylene cups: a radiostereometry analysis study. J Arthroplasty. 2005;20:409413.

36. Schafer JL. Analysis of Incomplete Multivariate Data. London, UK: Chapman and Hall; 1997.

37. Semlitsch M, Lehmann M, Weber H, Doerre E, Willert HG. New prospects for a prolonged functional life-span of artificial hip joints by using the material combination polyethylene/aluminium oxide ceramic/metal. J Biomed Mater Res. 1977;11:537-552.

38. Sjölander A, Lichtenstein P, Larsson H, Pawitan Y. Betweenwithin models for survival analysis. Stat Med. 2013:3067-3076.

39. Traina F, De Fine M, Di Martino A, Faldini C. Fracture of ceramic bearing surfaces following total hip replacement: a systematic review. Biomed Res Int. 2013;2013:157247.

40. van Buuren S. Multiple imputation of discrete and continuous data by fully conditional specification. Stat Methods Med Res. 2007;16:219-242.

41. White IR, Royston P. Imputing missing covariate values for the Cox model. Stat Med. 2009;28:1982-1998. 